\title{
EDITORIAL
}

\section{IN PRAISE OF HUNTING}

\author{
The long road to novel therapeutics relies on a multiplicity of disciplines, but above all it normally \\ depends on the hard-won experience of the drug hunter. Creating a truly prestigious award for \\ those who have mastered this skill would be one way of encouraging others to learn the craft.
}

The employment needs of pharmaceutical companies remain relatively constant, and although abundances and shortages of talented people in particular disciplines come and go, there is one skill generally agreed by all to be in a perpetual state of scarcity: the art of drug hunting. Some call it a 'nose' for the drug, some an 'eye', but however it is described, the ability to identify and doggedly pursue your quarry through the meandering and lengthy paths of the drug pipeline is a rare and essential attribute keenly sought out by the industry. Given the small number of drugs that most companies manage to bring through to market, and how long the whole process can take, it's no wonder that those with experience of success are few and far between. The drug hunters that do exist can be invaluable in passing on their knowledge to the new generation, encouraging others to develop an aptitude for drug discovery and development, and a liking for the thrill of the chase.

How can we best make use of these scarce human resources to improve the therapeutic prospects of the future? Certainly as role models for those deciding which career path to take. But the shining examples that young scientists considering their future careers strive to emulate are more likely to be Nobel laureates, with their contributions firmly rooted in the world of academic achievement, than drug scientists from industry. It's a safe bet that more doctoral students have daydreams of receiving that phone call from Stockholm than of being the key individual that drives a therapeutic of real medical value onto the market, although actually the chances of either happening must be fairly similar. Maybe with more publicity for the very best approaches to drug discovery we can encourage more of our most talented researchers to join in the hunt.

With these thoughts in mind, a group of about 70 academic and industrial scientists got together in Boston this spring for an evening discussion on the topic of awards for drug discovery and development. The topic under debate was whether such awards were needed and, if so, how they could be best organized. The discussions, made possible by the sponsorship of Spaulding \& Slye Colliers and moderated by Nature Reviews Drug Discovery, were led by a panel of local experts: Tom Maniatis, Judah Folkman and Fred Goldberg from Harvard, Steven Holtzman from Infinity Pharmaceuticals, and Ken Kaitin from Tufts. The consensus was that there are pressing reasons for creating such awards, but that their effectiveness would depend on the provision of funding from a patently unbiased endowment, their being highly exclusive, and the establishment of an awarding mechanism based on a thorough and independent nomination and selection procedure.

Awards, it was generally agreed, serve an important purpose by signalling what society considers the most worthwhile pursuits, and therefore a prestigious and high-profile prize for drug development would help to show what this field can be at its very best. Given the lessthan-transparent nature of much of the drug discovery process, those at the discussion identified the biggest problem facing any selection committee as being the elucidation of the real story behind a successful drug. The consensus was that beginning the process by identifying new drugs that make a substantial difference to people's lives and then working backwards to decipher the real story behind them would be the best way forward, an endeavour that would obviously require an expert committee and the commitment of a great deal of time and effort to get at the details. Although many people are involved in every drug's story, there was a feeling that it would be essential to limit the number of awardees to a very few individuals if the award was to fulfil its purpose.

There are already many prizes given for medical research, but no highly visible, entirely independent award that recognizes the distinct combination of ingenuity, energy and patience needed to capture a novel drug. The Nobel prizes contribute tremendously to the public face of basic science. Perhaps general appreciation of great drug research should be given a similar boost. 